\title{
Fosfatos de Fe e Mn primários e secundários em pegmatitos graníticos do Campo Pegmatítico Mata Azul, Jaú do Tocantins, TO, Brasil Primary and secondary $\mathrm{Fe}$ and Mn phosphates in granitic pegmatites from the Mata Azul Pegmatitic Field, Jaú do Tocantins, TO, Brazil
}

\author{
Hudson de Almeida Queiroz e Nilson Francisquini Botelho \\ Instituto de Geociências, Universidade de Brasília - UnB, SCLRN 708, bloco F, entrada 54, CEP 70740-556, Brasília, DF, BR \\ (hudsonq@gmail.com; nilsonfb@unb.br)
}

Recebido em 27 de setembro de 2016; aceito em 30 de março de 2017

\begin{abstract}
Resumo
No sul do Estado do Tocantins e norte do Estado de Goiás, pegmatitos graníticos estéreis e mineralizados são conhecidos e explorados há muito tempo, mas só recentemente foram caracterizados quanto aos aspectos mineralógicos, composicionais e genéticos e agrupados sob a denominação de Campo Pegmatítico Mata Azul. Em três desses corpos localizados no município de Jaú do Tocantins, com mineralização de berilo, fosfatos de Fe e Mn ocorrem sob a forma de nódulos ou massas centimétricas. Duas associações de fosfatos são diferenciadas. Na primeira delas, hospedada nos pegmatitos São Júlio e Pichorra, foram descritas três fases primárias, identificadas como zwieselita, sarcopsídio e fluorapatita. Processos hidrotermais alteram essas fases, formando rockbridgeíta, uma fase do subgrupo da alluaudita e heterosita. Na segunda associação, presente no pegmatito Fazenda Mesquita, não há sinal de fosfato primário e todas as fases presentes são secundárias. Rockbridgeíta, de cor verde a alaranjada, compõe boa parte do volume das amostras. Fosfosiderita e strengita aparecem como alterações da rockbridgeíta, às vezes preenchendo cavidades nas massas de fosfato. Nas duas associações, óxidos e hidróxidos de $\mathrm{Fe}$ e $\mathrm{Mn}$, oriundos da oxidação intempérica, correspondem às últimas fases formadas, podendo constituir crostas que recobrem boa parte dos nódulos e das massas de fosfatos. Em algumas amostras das associações de fosfatos, cristais de uraninita, gahnita, almandina e columbita-(Fe) foram identificados.
\end{abstract}

Palavras-chave: Fosfatos de Fe-Mn; Pegmatitos; Mata Azul.

\begin{abstract}
In central Brazil, in the southern Tocantins and in the northern Goiás States, barren and mineralized granitic pegmatites are known and explored for a long time, but only in recent years they were properly characterized and grouped in the so called Mata Azul Pegmatitic Field. In Jaú do Tocantins, three of the pegmatite bodies explored for beryl, a Fe-Mn phosphate associations occur as centimetric nodules and aggregates. Two phosphate associations were characterized: the first, hosted in Pichorra and São Júlio pegmatites present three primary phases, identified as zwieselite, sarcopside and fluorapatite. Hydrothermal processes transform the primary phosphates in rockbridgeite, heterosite and a phase of the alluaudite subgroup. The second association was observed in the Fazenda Mesquita pegmatite, where primary phosphates are absent and orange to green rockbridgeite is the main phase, followed by phosphosiderite and strengite formed by the weathering of rockbridgeite. In both associations, the weathering of the Fe-Mn phosphates give rise to Fe and Mn oxides. Minor phases as uraninite, gahnite, almandine and columbite-(Fe) were identified as inclusions in the phosphate phases.
\end{abstract}

Keywords: Fe-Mn phosphates; Pegmatites; Mata Azul. 


\section{INTRODUÇÃO}

O estudo de associações fosfáticas em pegmatitos é sensível aos diferentes estágios de evolução do corpo (Fransolet, 2007). Indicações do estágio de evolução do magma pegmatítico utilizando o teor de elementos como Li, F e P, e a razão $\mathrm{Fe} / \mathrm{Mn}$ podem ser dados por fosfatos primários, por exemplo. Alterações hidrotermais e intempéricas de fosfatos preexistentes podem, ainda, aumentar consideravelmente $o$ número de fases fosfáticas presentes, resultando em complexas paragêneses de grande interesse mineralógico.

Na parte central do Brasil, vários corpos pegmatíticos ocorrem espalhados por uma área que abrange os Estados de Goiás e Tocantins. Muitos desses pegmatitos hospedaram garimpos de gemas por várias décadas; hoje, a maioria se encontra abandonada. No sul do Estado do Tocantins, no município de Jaú do Tocantins, alguns garimpos de berilo (industrial e gema) foram visitados para descrição mineralógica. Apesar de as cavas estarem obstruídas ou cobertas de água, no rejeito de três garimpos, Pichorra, São Júlio e Fazenda Mesquita, vários fragmentos de agregados de fosfatos foram encontrados na forma de nódulos e massas centimétricas. Vários trabalhos sobre fosfatos em pegmatitos já foram descritos na Província Pegmatítica Oriental, em Minas Gerais (Chaves et al., 2005; Scholz, 2006; Chaves e Scholz, 2008; Baijot et al., 2014; Chukanov et al., 2014); considerando que pegmatitos foram pouco estudados do Brasil Central, esta é a primeira descrição de uma assembleia de fosfatos de Fe e Mn.

\section{SÍNTESE GEOLÓGICA}

Os pegmatitos portadores dos fosfatos de Fe e Mn estão localizados na parte central da Província Tocantins, que compreende um sistema orogênico formado por extensas faixas de dobramentos, entre elas a Faixa Brasília, na qual a área de estudo está inserida, localizada no município de Jaú do Tocantins, próximo à divisa com o Estado de Goiás (Figura 1). A região possui um embasamento metassedimentar de fácies anfibolito denominado Formação Ticunzal, constituído por diferentes tipos de xisto e paragnaisses. Alvarenga et al. (2007) inserem rochas da formação Ticunzal, aflorantes a sudeste da área de estudo, no Paleoproterozoico. Intrudindo esse embasamento estão as Suítes Aurumina e Rio das Almas: a primeira compreende rochas graníticas peraluminosas foliadas; a segunda suíte é constituída por granodioritos e gnaisses (Araújo Filho et al., 2017). O Grupo Serra da Mesa, com idade de deposição estimada entre 1,47 e 1,57 Ga (Dardenne, 2000; Marques, 2009), cobre boa parte da região com rochas metassedimentares sílico-carbonáticos deformadas e metamorfisadas durante a orogenia Brasiliana no Neoproterozoico. A Suíte do Peixe, intrusiva no grupo
Serra da Mesa, é formada por sienogranitos, nefelina sienitos e pegmatitos alcalinos de 1,5 a 1,47 Ga (Kitajima et al., 2001) para os nefelina sienitos, que não são relacionados composicionalmente aos pegmatitos aqui estudados.

Conforme proposto por Queiroz (2016), os pegmatitos portadores de fosfatos de $\mathrm{Fe}$ e $\mathrm{Mn}$ são relacionados à Suíte Mata Azul, que é composta por leucogranitos evoluídos do neoproterozoico associados à evolução do Arco Magmático de Mara Rosa. A ocorrência desses granitos só é conhecida no norte do Estado de Goiás, nas proximidades da divisa com o Estado de Tocantins, não tendo sido, até agora, mapeados na região de ocorrência dos fosfatos (Figura 1).

\section{MÉTODOS ANALÍTICOS}

Várias seções delgadas das massas de fosfato foram confeccionadas para os estudos das fases minerais, primeiramente com a observação e a descrição das paragêneses sob microscópio de luz polarizada.

Análises químicas pontuais foram feitas em uma sonda eletrônica JEOL, modelo superprobe JXA-8230, utilizando voltagem de $15 \mathrm{kV}$ e corrente de $10 \mathrm{nA}$. Os padrões empregados foram: albita $(\mathrm{Na})$, microclínio $(\mathrm{K}, \mathrm{Al}), \mathrm{ZnO}$ vidro $(\mathrm{Zn})$, forsterita $(\mathrm{Mg})$, andradita $(\mathrm{Si}, \mathrm{Ca}, \mathrm{Fe})$, topázio $(\mathrm{F})$,

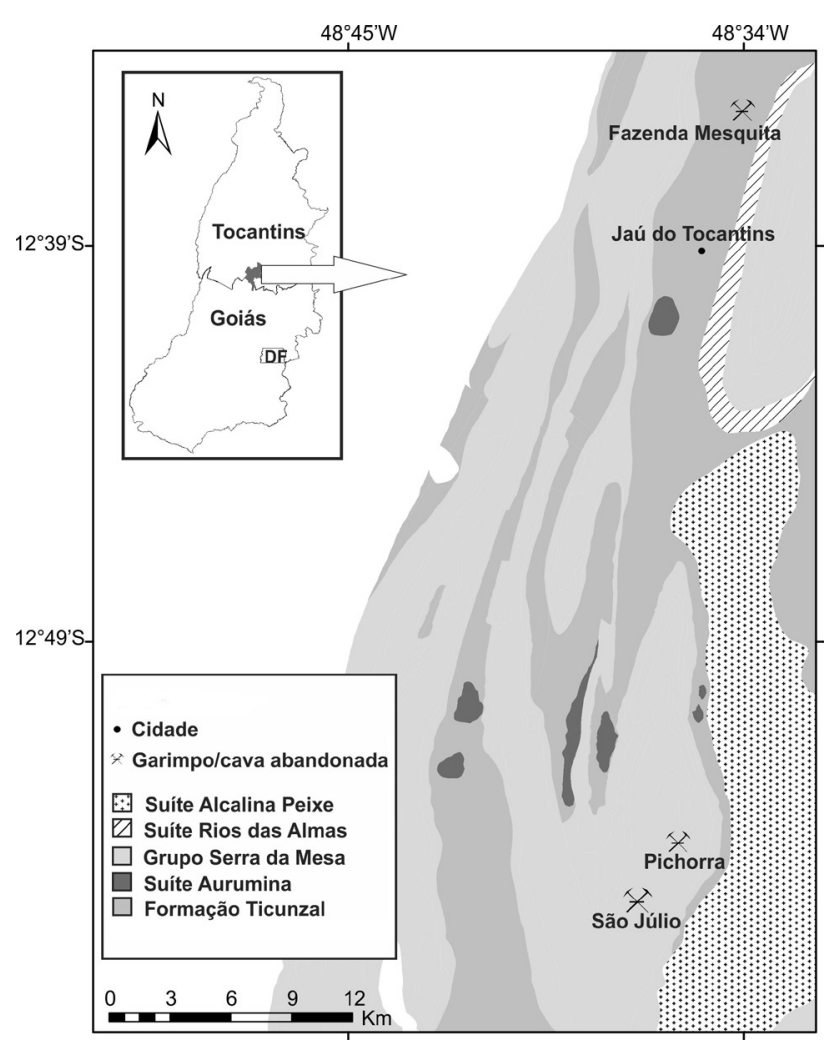

Figura 1. Mapa geológico com a localização dos pegmatitos hospedeiros de fosfatos de Fe-Mn. 
pirofanita $(\mathrm{Mn})$ e apatita $(\mathrm{P})$. Imagens por microscópio eletrônico de varredura foram feitas em um aparelho FEI Quanta 450.

Análises de microsespectroscopia Raman utilizaram um espectrômetro triplo Jobin Yvonspex Horiba, modelo T64000, com objetiva de 50x e detector CCD refrigerado a nitrogênio líquido, e o espectro Raman foi excitado por um laser de argônio (514,5 nm), com potência de saída de $100 \mathrm{~mW}$ e filtro de plasma na linha de $514,5 \mathrm{~nm}$. O tempo de aquisição foi de 10 segundos com integração de $3 x$.

A identificação de fases por meio da difração de raios $\mathrm{X}$ foi realizada em um difratômetro Rigaku modelo Ultima IV, com tubo de cobre, filtro de níquel em $35 \mathrm{kV}$ e $15 \mathrm{~mA}$, e a varredura da amostra foi feita em $5 \% \mathrm{~min}$. no intervalo $2 \theta$ de 3 a $80^{\circ}$.

\section{OS PEGMATITOS DO SUBTIPO BERILO-COLUMBITA-FOSFATO}

Os pegmatitos com ocorrências de fosfatos de $\mathrm{Fe}$ e $\mathrm{Mn}$ pertencem à família LCT e fazem parte de um grupo de pegmatitos com mineralização principal de berilo, do subtipo berilo-columbita-fosfato, segundo classificação de Černý e Ercit (2005); também compõem o campo pegmatítico da Suíte Mata Azul (Queiroz, 2016).

Os pegmatitos que hospedam os fosfatos já foram alvo de garimpeiros em busca de berilo, em especial água-marinha. Esses corpos possuem exposição limitada, estando há muito tempo encobertos pela vegetação ou por água. Os diques pegmatíticos apresentam-se bastante intemperizados, constituindo-se principalmente por caulinita, com quantidades variáveis de muscovita, quartzo e raramente biotita. Nas pilhas de rejeito, cristais de feldspato potássico ainda pouco alterado podem ser encontrados, junto de grandes blocos de quartzo com muscovita e berilo, na maior parte de coloração verde clara a azul clara, com alguns poucos cristais tendendo à cor amarela. No pegmatito São Júlio, cristais de schorlita também são facilmente encontrados, além de fragmentos de um agregado de microcristais de muscovita de coloração verde clara.

Os fosfatos são encontrados sob a forma de nódulos e massas contendo, em grande parte, duas ou mais fases minerais. Apesar de as amostras não estarem in situ, presume-se que são produtos finais da cristalização do corpo pegmatítico devido à ocorrência em conjunto com grandes blocos de quartzo, típicos das zonas mais internas do pegmatito. Outras fases minerais podem ser encontradas dentro das massas fosfáticas, por exemplo, almandina, uraninita, gahnita e columbita-(Fe), sempre em pouca quantidade. Além desses minerais, óxidos e hidróxidos de $\mathrm{Fe}$ e $\mathrm{Mn}$ preenchem fraturas e envolvem alguns nódulos e massas de fosfatos (Tabela 1).

\section{PETROGRAFIA DOS FOSFATOS}

Existem duas associações de fosfatos nos pegmatitos visitados (Tabela 2). A primeira, encontrada nos garimpos Pichorra e São Júlio, é caracterizada pela presença de fases primárias e secundárias de fosfatos. Na segunda associação, encontrada nos agregados do pegmatito Fazenda Mesquita, apenas fases secundárias puderam ser identificadas.

\section{Associação de fosfatos I}

Boa parte das amostras da associação I é formada por massas anédricas de uma fase dentro da solução sólida zwieselita $(\mathrm{Fe}, \mathrm{Mn})_{2}\left(\mathrm{PO}_{4}\right) \mathrm{F}$ - triplita $(\mathrm{Mn}, \mathrm{Fe}, \mathrm{Mg}, \mathrm{Ca})_{2}\left(\mathrm{PO}_{4}\right)(\mathrm{F}, \mathrm{OH})$, com maior tendência para a composição da zwieselita (Figura 2). Esse fosfato com coloração de bege a castanho claro (e, algumas vezes, salmão) corresponde à fase de fosfato dominante e pode ser considerado como de origem

Tabela 1. Composição química de alguns minerais dos pegmatitos portadores de berilo e fosfatos.

\begin{tabular}{|c|c|c|c|}
\hline & Schorlita & Almandina & Muscovita \\
\hline$\overline{\mathrm{SiO}_{2}}$ & 34,69 & 34,97 & 45,57 \\
\hline $\mathrm{TiO}_{2}^{2}$ & 0,37 & & 0 \\
\hline $\mathrm{Al}_{2} \mathrm{O}_{3}$ & 30,84 & 22,13 & 34,50 \\
\hline $\mathrm{FeO}$ & 16,45 & 31,41 & 3,63 \\
\hline $\mathrm{MnO}$ & 2,30 & 10,71 & 0,10 \\
\hline $\mathrm{MgO}$ & 0,14 & 0,11 & 0,31 \\
\hline $\mathrm{CaO}$ & 0,01 & 0,05 & 0,01 \\
\hline $\mathrm{Na}_{2} \mathrm{O}$ & 2,74 & & 0,65 \\
\hline $\mathrm{K}_{2} \mathrm{O}^{2}$ & 0,02 & & 10,27 \\
\hline $\mathrm{F}^{2}$ & 0,71 & & 1,54 \\
\hline $\mathrm{H}_{2} \mathrm{O}^{*}$ & 3,17 & & 3,73 \\
\hline $\mathrm{B}_{2} \mathrm{O}_{3}{ }^{*}$ & 10,17 & & \\
\hline $\mathrm{Li}_{2} \mathrm{O}^{*}$ & 0,13 & & 0,40 \\
\hline Total & 101,43 & 99,38 & 100,05 \\
\hline $\mathrm{O}=\mathrm{F}$ & 0,30 & & 0,65 \\
\hline \multicolumn{4}{|c|}{ Átomos por fórmula unitária } \\
\hline $\mathrm{Si}$ & 5,931 & 2,886 & 6,123 \\
\hline $\mathrm{Ti}$ & 0,048 & & 0 \\
\hline $\mathrm{Al}$ & 6,214 & 2,164 & 5,465 \\
\hline $\mathrm{Fe}$ & 2,352 & 2,233 & 0,408 \\
\hline $\mathrm{Mn}$ & 0,333 & 0,749 & 0,011 \\
\hline Mg & 0,036 & 0,014 & 0,061 \\
\hline $\mathrm{Ca}$ & 0,002 & 0,004 & 0,002 \\
\hline $\mathrm{Na}$ & 0,908 & & 0,169 \\
\hline K & 0,004 & & 1,760 \\
\hline$F$ & 0,384 & & 0,654 \\
\hline $\mathrm{OH}$ & 3,616 & & 3,346 \\
\hline B & 3 & & \\
\hline $\mathrm{Li}$ & 0,087 & & 0,218 \\
\hline
\end{tabular}

*óxidos e elementos calculados. B em apfu fixado no valor ideal de 3 . 
primária, assim como cristais euédricos a subédricos de fluorapatita que abundam em algumas porções das amostras estudadas (Figura 3).

Os cristais de zwieselita comumente mostram alterações com padrões variados. O primeiro deles tem aspecto "mosqueado" de difícil identificação e provavelmente corresponde a uma primeira etapa de alteração. Progressivamente, o fosfato primário dá lugar a massas de heterosita $-\left(\mathrm{Fe}^{3+}, \mathrm{Mn}^{3+}\right)$ $\mathrm{PO}_{4}$, inicialmente com coloração vermelha escura, passando à coloração roxa ou púrpura (Figura 3). Óxidos de $\mathrm{Fe}$ e/ou Mn podem também se formar junto à massa de heterosita.

Duas fases minerais se formam a partir da alteração da heterosita e ocorrem juntas em um agregado de finos cristais com coloração de amarelo a laranja, em limitadas áreas das amostras coletadas (Figura 3). Os cristais

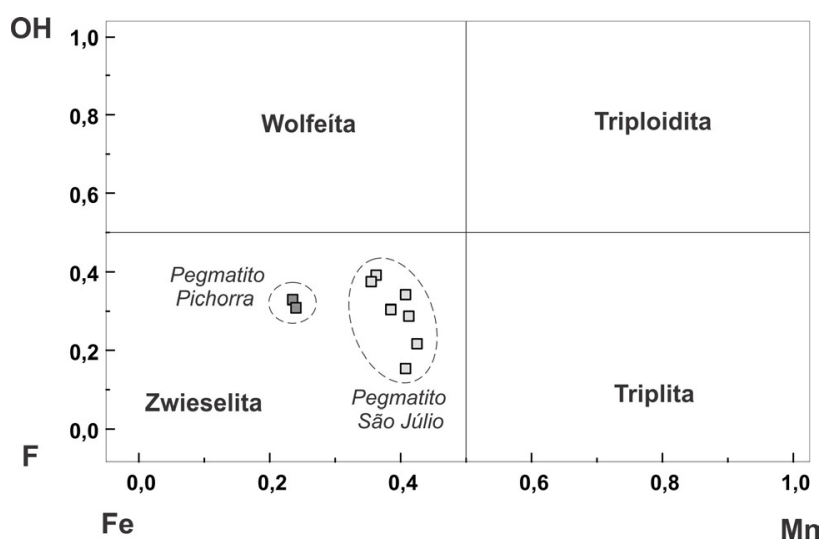

Figura 2. Classificação do fosfato primário zwieselita na associação I. Valores em apfu.

Tabela 2. Composição representativa de fosfatos das associações I e II.

\begin{tabular}{|c|c|c|c|c|c|c|c|c|}
\hline & Zwieselita & Sarcopsídio & $\begin{array}{l}\text { Heterosita } \\
\text { roxa }\end{array}$ & $\begin{array}{l}\text { Subgrupo } \\
\text { da } \\
\text { Alluaudita }\end{array}$ & $\begin{array}{l}\text { Rockbridgeíta } \\
\text { verde }\end{array}$ & $\begin{array}{c}\text { Fosfosiderita } \\
\text { bege }\end{array}$ & $\begin{array}{c}\text { Strengita } \\
\text { rosa }\end{array}$ & Fluorapatita \\
\hline $\mathrm{P}_{2} \mathrm{O}_{5}$ & 31,78 & 39,46 & 47,62 & 46,04 & 35,04 & 43,48 & 42,12 & 41,44 \\
\hline $\mathrm{FeO}$ & 34,92 & 44,43 & & $3,24^{*}$ & $3,71^{*}$ & & & 0,93 \\
\hline $\mathrm{Fe}_{2} \mathrm{O}_{3}$ & & & 40,01 & 16,77 & 47,33 & 45,74 & 40,27 & \\
\hline $\mathrm{MnO}$ & 24,21 & 12,04 & & 25,85 & 7,52 & 0,61 & 1,65 & 1,69 \\
\hline $\mathrm{Mn}_{2} \mathrm{O}_{3}$ & & & 11,24 & & & & & \\
\hline $\mathrm{MgO}$ & 1,2 & 0,19 & 0,25 & 0,22 & 0,00 & 0,03 & 0,00 & \\
\hline $\mathrm{CaO}$ & 0,79 & 0,01 & 0,38 & 0,16 & 0,07 & 0,03 & 0,02 & 53,08 \\
\hline $\mathrm{Na}_{2} \mathrm{O}$ & 0,12 & 0,04 & & 8,35 & 0,17 & 0,12 & 0,06 & \\
\hline $\mathrm{K}_{2} \mathrm{O}$ & & 0,01 & 0,89 & 0,14 & 0,00 & 0,02 & 0,07 & \\
\hline F & 6,53 & & & & & & & 3,44 \\
\hline $\mathrm{O}=\mathrm{F}$ & 2,75 & & & & & & & 1,45 \\
\hline Total & 96,80 & 96,19 & 100,39 & 100,77 & 92,49 & 90,03 & 84,19 & 99,13 \\
\hline \multicolumn{9}{|c|}{ Átomos por fórmula unitária } \\
\hline$P$ & 0,931 & 2,037 & 0,966 & 3,125 & 3,133 & 1,020 & 1,048 & 2,881 \\
\hline $\mathrm{Fe}^{2}$ & 1,010 & 2,265 & & 0,217 & 0,327 & & & 0,064 \\
\hline $\mathrm{Fe}^{3}$ & & & 0,721 & 1,012 & 3,762 & 0,954 & 0,890 & \\
\hline $\mathrm{Mn}^{2}$ & 0,710 & 0,622 & & 1,755 & 0,673 & 0,014 & 0,041 & 0,118 \\
\hline $\mathrm{Mn}^{3}$ & & & 0,314 & & & & & \\
\hline $\mathrm{Mg}$ & 0,062 & 0,017 & 0,010 & 0,026 & 0,000 & 0,001 & & \\
\hline $\mathrm{Ca}$ & 0,029 & 0,001 & 0,010 & 0,014 & 0,008 & 0,001 & 0,001 & 4,670 \\
\hline $\mathrm{Na}$ & 0,008 & 0,005 & & 1,298 & 0,033 & 0,006 & 0,003 & \\
\hline K & & 0,001 & 0,027 & 0,014 & 0,000 & 0,001 & 0,003 & \\
\hline $\mathrm{F}$ & 0,715 & & & & & & & 0,893 \\
\hline
\end{tabular}

Cálculo de apfu feito com base em 4 oxigênios para fosfosiderita, strengita e heterosita, 4,5 oxigênios para zwieselita, 8 oxigênios para sarcopsídio, 12 oxigênios para mineral do subgrupo da alluaudita e apatita e 14,5 oxigênios para rockbridgeíta. 

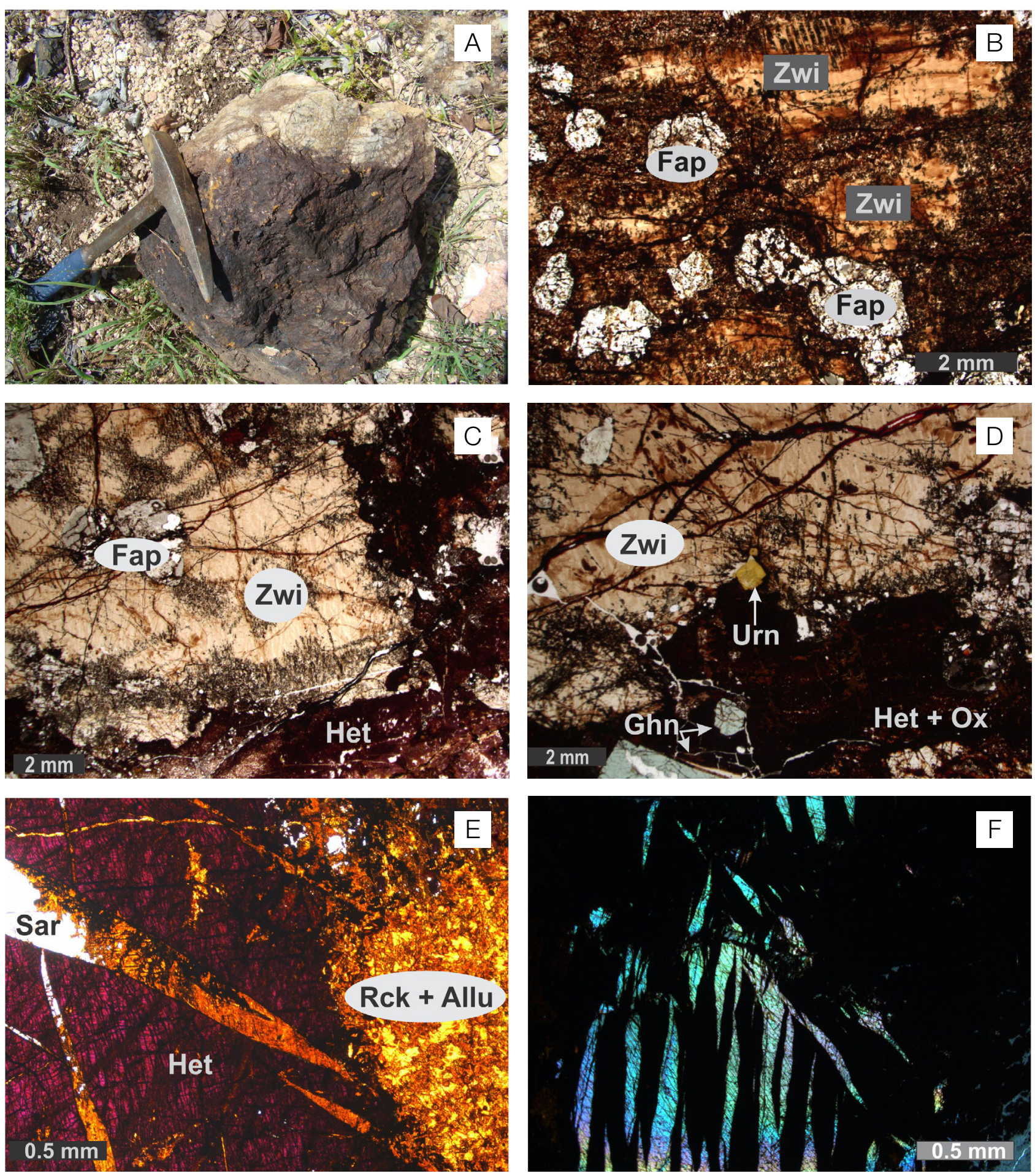

Zwi: zwieselita; Fap: fluorapatita; Het: heterosita; Urn: uraninita; Ghn: gahnita; Ox: óxidos; Rck: rockbridgeíta; Sar: sarcopsídeo; Allu: minerais do subgrupo da alluaudita.

Figura 3. Fosfatos da associação I. (A) bloco com quartzo e agregado maciço de fosfatos (P//). (B) cristal de zwieselita castanho em estágio de alteração (aspecto granulado) e cristais brancos de fluorapatita. (C) zwieselita castanha alterando para massa de heterosita avermelhada. (D) zwieselita castanha, com massa de alteração composta por heterosita e óxidos de $\mathrm{Mn}$ e Fe, além de cristal cúbico amarelo de uraninita no centro da imagem e cristais azulados de gahnita na parte inferior. (E) associação com heterosita roxa, lamelas de sarcopsídio incolor, alterando-se para minerais do grupo da alluaudita de cor laranja e massa laranja e amarela constituída por minerais do grupo da alluaudita e rockbridgeíta. (F) lamelas de sarcopsídio em massa de heterosita + opacos (PX). 
amarelos mostram composição química similar à série frondelita-rockbridgeíta - $\left(\mathrm{Mn}^{2+} \mathrm{Fe}^{2+}\right) \mathrm{Fe}^{3+} 4\left(\mathrm{PO}_{4}\right)_{3}(\mathrm{OH})_{6}$, com tendência para composição mais rica em Fe da rockbridgeíta. Os cristais laranjas, mais abundantes, são, por sua vez, identificados como uma fase mineral do subgrupo da alluaudita-willyeíta e talvez um membro da série varulita - $(\mathrm{Na}, \mathrm{Ca}) \mathrm{Mn}^{2+}\left(\mathrm{Mn}^{2+}, \mathrm{Fe}^{2+}, \mathrm{Fe}^{3+}\right)_{2}\left(\mathrm{PO}_{4}\right)_{3}$ - hagendorfita $-\mathrm{NaCaMn}^{2+}\left(\mathrm{Fe}^{2+}, \mathrm{Fe}^{3+}, \mathrm{Mg}\right)_{2}\left(\mathrm{PO}_{4}\right)_{3}$, incluído no subgrupo da alluaudita.

Em determinadas porções das amostras, ocorre uma associação de heterosita, minerais do subgrupo da alluaudita e sarcopsídio - $\left(\mathrm{Fe}^{2+}, \mathrm{Mn}^{2+}, \mathrm{Mg}\right)_{3}\left(\mathrm{PO}_{4}\right)_{2}$. Sarcopsídio aparece sob a forma de lamelas incolores em duas direções distintas (Figura 3), como se acompanhasse planos de clivagem. Em algumas lamelas de sarcopsídio, o cristal mostra-se parcialmente alterado, com finas vênulas de oxidação, até ser totalmente substituído por minerais do subgrupo da alluaudita.

Substituindo os fosfatos ou preenchendo fraturas, abundam muitos óxidos. Aqueles compostos predominantemente por Fe podem formar agregados centimétricos de hematita, enquanto as fases com Mn e algum conteúdo de $\mathrm{K}$ ou $\mathrm{Ba}$ indicam, respectivamente, ocorrências de criptomelano e hollandita.

\section{Associação de fosfatos II}

A associação de fosfatos II está presente em amostras do pegmatito da Fazenda Mesquita, na qual não foram encontrados indícios de fosfato primário. O grau de alteração em algumas massas fosfáticas é tal, que uma crosta de óxidos e hidróxidos de Fe é constituída, principalmente, por goethita, que mostra um hábito reniforme típico. Óxido de $\mathrm{Mn}$ também é comumente encontrado, preenchendo fraturas ou sob a forma de finas crostas.

Grande parte do volume de fosfatos é formada por um agregado anédrico, ou radial em algumas porções, de rockbridgeíta verde escura (Figura 4) que pode, pontualmente, adquirir coloração laranja devido a um maior grau de oxidação, sem modificação importante na constituição química.

Rockbridgeíta se altera principalmente para fosfosiderita $-\mathrm{Fe}^{3+} \mathrm{PO}_{4}, 2 \mathrm{H}_{2} \mathrm{O}$, que forma massas anédricas de cor bege a amarelada até aglomerados botrioidais (Figura 4). Nos agregados de fosfatos é comum a ocorrência de pequenas cavidades, em geral com poucos centímetros, envoltas por rockbridgeíta e fosfosiderita. Essas cavidades, em sua maior parte, possuem cristais prismáticos bem formados de strengita $-\mathrm{Fe}^{3+} \mathrm{PO}_{4} 2 \mathrm{H}_{2} \mathrm{O}$ (Figura 4), que também podem assumir a forma de pequenos esferulitos, com coloração variando entre branca, rosa e roxa, muitas vezes em um mesmo cristal. Os resultados de espectroscopia Raman (Figura 5) ajudam a diferenciar entre os polimorfos fosfosiderita e strengita, baseando-se no trabalho de Frost et al. (2004) e no banco de dados RRUFF (Lafuente et al., 2015).

\section{DISCUSSÃO E SEQUÊNCIA DE ALTERAÇÃO}

Três fases primárias fazem parte da associação I de fosfatos, são elas: zwieselita, a mais abundante; sarcopsídio; e apatita. London et al. (1999), em trabalho experimental com fases silicáticas e fosfáticas, discutem que o alto conteúdo inicial de $\mathrm{Ca}$ e $\mathrm{F}$ em uma triplita pode promover a saturação do melt nesses elementos, o que explicaria a ocorrência, aqui observada, de fluorapatita em equilíbrio com a zwieselita.

Moore (1972) sugere a existência de uma solução sólida de alta temperatura para o intercrescimento entre sarcopsídio e trifilita, na qual o sarcopsídio é derivado da estrutura da trifilita (Moore, 1984). Entre as ocorrências conhecidas dessa associação, pode-se citar aquela descrita por Roda-Robles e Pesquera (2014). Como já exposto, lamelas de sarcopsídio são encontradas junto a massas de heterosita de origem secundária, o que indica que o fosfato primário do qual o sarcopsídio se exsolveu já foi totalmente alterado, trifilita ou zwieselita, esta última identificada na associação I, podem ser apontadas como as possíveis fases primárias.

A sequência de alteração proposta (Figura 6) inicia-se com a zwieselita, na qual massas de heterosita se formam por alteração hidrotermal, a princípio como pequenas inclusões no fosfato primário. Nos estágios menos alterados, a heterosita tem uma coloração vermelha escura - por vezes com um tom tão escuro que se assemelha à cor de minerais opacos. Em alguns casos, há de fato uma mistura de óxidos de $\mathrm{Fe}$ e $\mathrm{Mn}$ e fosfatos nessas massas escuras. À medida que há um aumento de oxidação dos cristais de heterosita, a cor desse mineral se aproxima mais de um roxo intenso, o flúor da zwieselita é lixiviado, Fe é oxidado e é provável que, em estágios mais avançados de alteração, naqueles cristais de cor roxa, o Mn se oxide.

Os cristais de sarcopsídio parecem resistir melhor à primeira fase de alteração, apenas algumas vênulas de óxido de ferro são observadas ao longo dos planos de clivagem dos cristais.

Em áreas bem localizadas dos nódulos de fosfatos da associação I, outro tipo de alteração tardia está presente; nesse caso gerando um metassomatismo com entrada de Na. Esse tipo de alteração em especial parece cobrir apenas porções restritas; como não há amostras in situ, é difícil associá-la a uma paragênese mineral específica ou a uma zona do pegmatito. Ela é formada predominantemente por cristais do subgrupo da alluaudita, pela química mineral, possivelmente de um membro da série varulita - hagendorfita. 

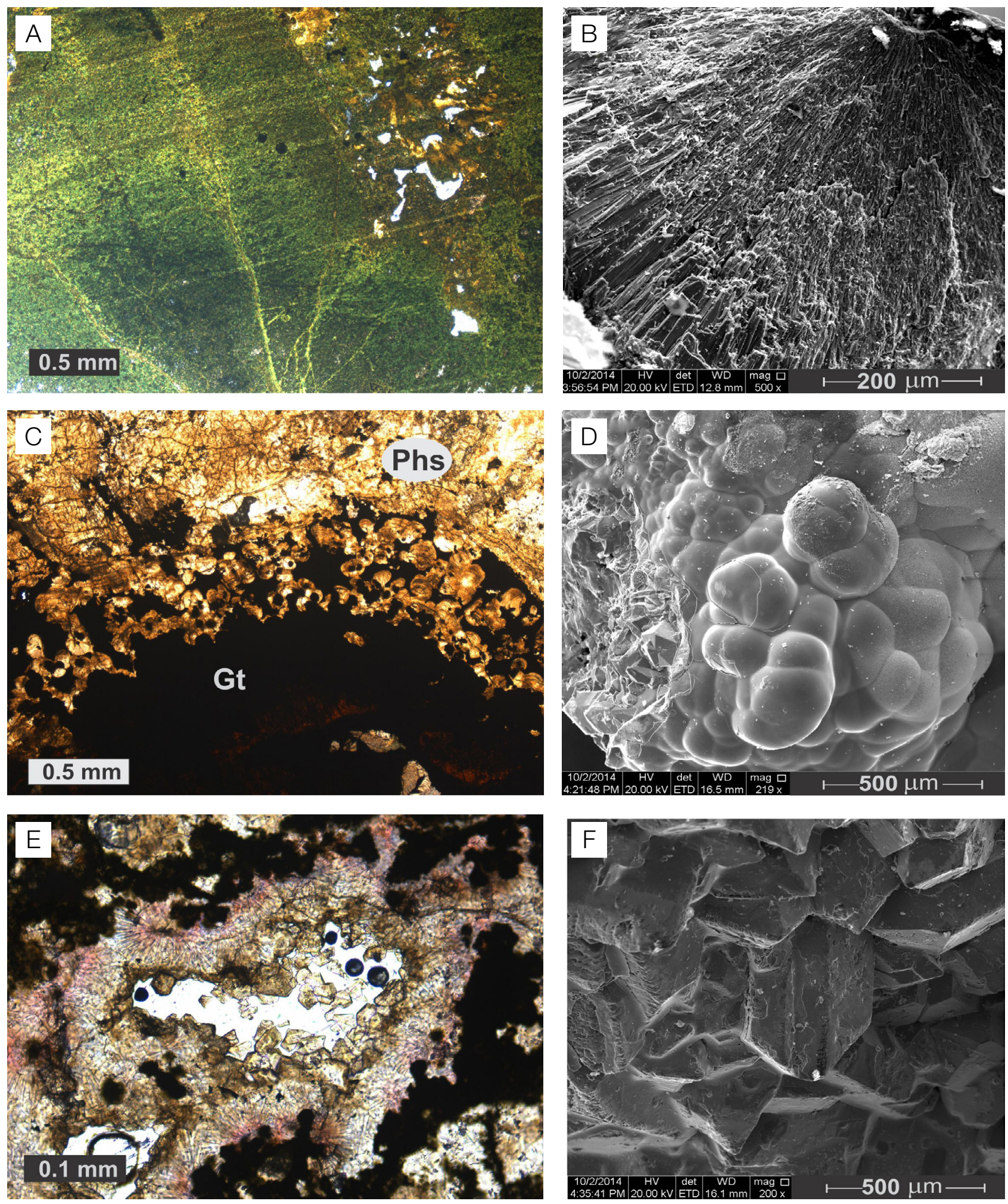

Phs: fosfosiderita; Gt: goethita.

Figura 4. Fotomicrografias e imagens por MEV da associação II. (A) massa anédrica verde de rockbridgeíta. (B) aspecto radial da rockbridgeíta em algumas porções das amostras. (C) fosfosiderita amarelada maciça na parte superior da foto passando a pequenos esferulitos no centro, na porção inferior uma massa de alteração formada por goethita. (D) aspecto botrioidal da fosfosiderita em uma cavidade. (E) cristais esferulíticos e prismáticos de strengita. (F) aspecto prismático de cristal de strengita em cavidade. 


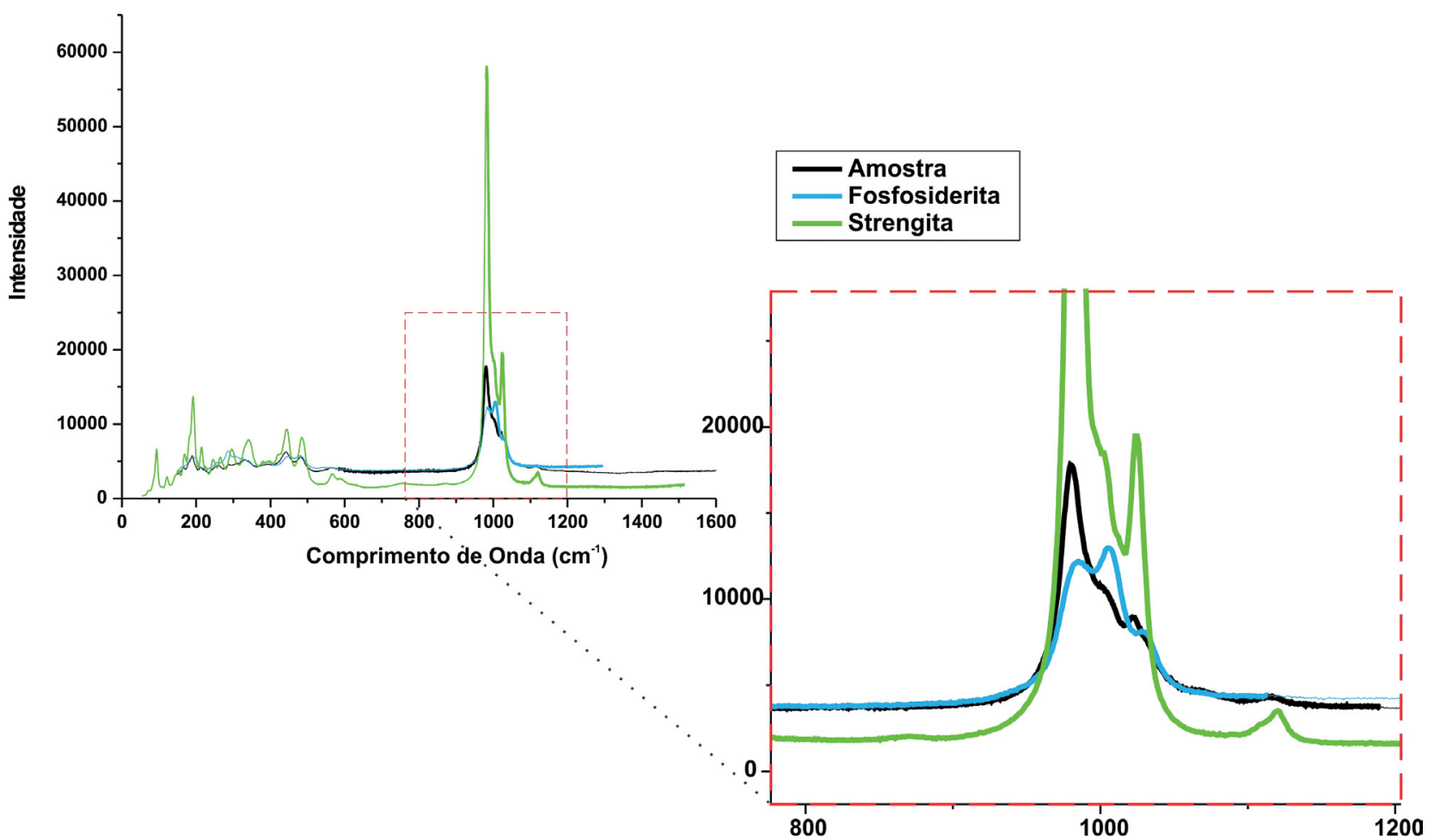

Figura 5. Espectro Raman de uma amostra de cavidade comparada a fosfosiderita e strengita do banco de dados RRUFF, com detalhe para a faixa entre 800 e $1200 \mathrm{~cm}^{-1}$, em que os picos são mais distintivos.

\section{ASSOCIAÇÃO II}

\section{ASSOCIAÇÃO I}

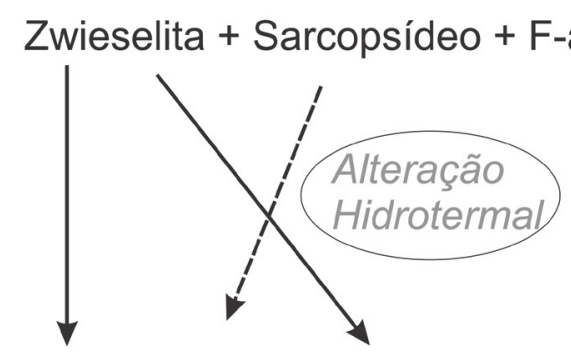

Rockbridgeíta

$+$

Hagendorfita

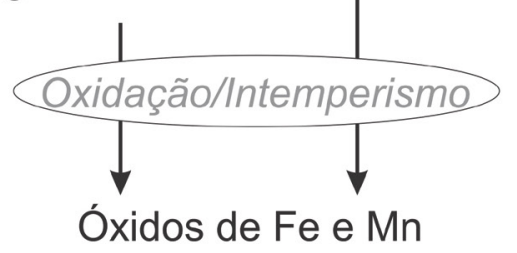

Fosfato Primário (?)

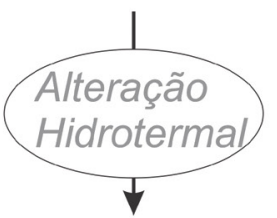

Rockbridgeíta

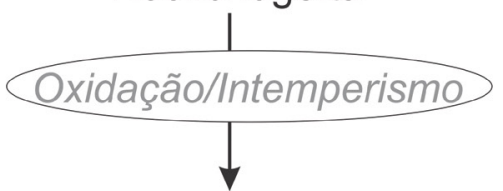

Fosfosiderita

$+$

Strengita

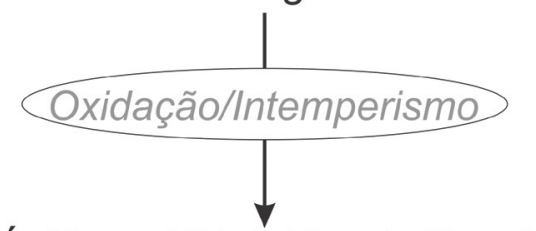

Óxidos e Hidróxidos de Fe e Mn

Figura 6. Esquema de alteração para as associações de fosfatos. 
Os óxidos de Fe e Mn podem se formar em vários estágios de alteração, mas principalmente na fase mais tardia de oxidação, preenchendo fraturas e formando crostas.

$\mathrm{Na}$ associação de fosfatos II, todo o fosfato primário que não foi encontrado parece ter se transformado em rockbridgeíta, muito provavelmente por alteração hidrotermal. A rockbridgeíta, por processo subsequente de oxidação, transforma-se em fosfosiderita; quando em contato com cavidades preexistentes, a strengita é o fosfato gerado. Outros produtos da oxidação intempérica são os óxidos e hidróxidos de $\mathrm{Mn}$ e $\mathrm{Fe}$, principalmente a goethita, que forma crostas e massas junto aos fosfatos; em muitas porções, esse hidróxido de Fe apresenta um hábito reniforme típico e, ao mesmo tempo, herdado da rockbridgeíta (Figura 4).

\section{CONCLUSÕES}

Em pegmatitos graníticos do Brasil Central, amostras de fosfatos de Fe e Mn de corpos com mineralização de berilo foram caracterizadas nas áreas pertencentes aos garimpos São Júlio, Pichorra e Fazenda Mesquita. Os fosfatos descritos compreendem duas associações distintas, a primeira composta pelas fases primárias: zwieselita, sarcopsídio e F-apatita, que se alteram para rockbridgeíta, heterosita e possivelmente hagendorfita, essa associação é presente nos pegmatitos São Júlio e Pichorra. A segunda associação é formada apenas por fases de alteração, principalmente rockbridgeíta, além desta, fosfosiderita e strengita aparecem em menor proporção, o pegmatito Fazenda Mesquita hospeda essa paragênese. Em ambas as associações, óxidos e hidróxidos de Fe e Mn aparecem em proporções variáveis.

Apesar de o volume de amostras coletadas não ser grande, muito por conta das condições de exposição dos corpos pegmatíticos, a continuidade de trabalhos de exploração desses e outros pegmatitos do sul do Tocantins pode ainda fornecer importantes informações sobre a mineralização das associações de fosfatos e caracterização de novas fases minerais nessas rochas de paragênese exótica.

\section{REFERÊNCIAS}

Alvarenga, C. J. S., Botelho, N. F., Dardenne, M. A., Lima, O. N. B., Machado, M. A. (2007). Programa geologia do Brasil: Geologia da folha Cavalcante. 67p. Escala 1:100.000. Nota explicativa. Goiás: UnB/CPRM.

Araújo Filho, O., Toledo, C. L., Carmelo, A. C., Almeida, T., Ferreira, G. (2017). Mapeamento da folha Jaú (em preparação).
Baijot, M., Hatert, F., Dal Bo, F., Philippo, S. (2014). Mineralogy and petrography of phosphate mineral associations from the Jocão Pegmatite, Minas Gerais, Brazil. The Canadian Mineralogist, 52, 373-397.

Černý, P., Ercit, T. S. (2005). The classification of granitic pegmatites revisited. The Canadian Mineralogist, 43(6), 2005-2026.

Chaves, M. L. S. C., Scholz, R. (2008). Pegmatito Gentil (Mendes Pimentel, MG) e suas paragêneses mineralógicas de fosfatos raros. Rem: Revista Escola de Minas, 61, 141-149.

Chaves, M. L. S. C., Scholz, R., Atencio, D., Karfunkel, J. (2005). Assembléias e paragêneses minerais singulares nos pegmatitos da região de Galiléia (Minas Gerais). Geociências, 24, 143-161.

Chukanov, N. V., Scholz, R., Zubkova, N. V., Pekov, I. V., Belakovskiy, D. I., Van, K. V., Lagoeiro, L., Graça, L. M., Krambrock, K., de Oliveira, L. C. A., Menezes Filho, L. A. D., Chaves, M. L. S. C., Pushcharovsky, D. Y. (2014). Correianevesite, $\mathrm{Fe}^{2+} \mathrm{Mn}_{22}\left(\mathrm{PO}_{4}\right)_{2} \cdot 3 \mathrm{H}_{2} \mathrm{O}$, a new reddingitegroup mineral from the Cigana mine, Conselheiro Pena, Minas Gerais, Brazil. American Mineralogist, 99, 811-816.

Dardenne, M. A. (2000). The Brasília fold belt. In: U. G. Cordani, E. J.Milani, A. Thomaz Filho, D. A. Campos (Eds.), Tectonic evolution of South America (231-263). $31^{\text {st }}$ International Geological Congress.

Fransolet, A. M. (2007). Phosphate associations in the granitic pegmatites : the relevant significance of these accessory minerals. $3^{\text {th }} P E G, 5-6$. Porto.

Frost, R. L., Weier, M. L., Erickson, K. L., Carmondy, O., Mills, S. J. (2004). Raman spectroscopy of phosphates of the variscite mineral group. Journal of Raman Spectroscopy, $35,1047-1055$.

Kitajima, L. F. W., Ruiz, J., Gehrels, G., Gaspar, J. C. (2001). Uranium-lead ages of zircon megacrysts and zircon included in corundum from Peixe Alkaline Complex (Brazil). III Simpósio Sudamericano de Geologia Isotópica. Pucón.

Lafuente, B., Downs, R. T., Yang, H., Stone, N. (2015). The power of databases: the RRUFF project. In: Highlights in Mineralogical Crystallography, T Armbruster and R M Danisi, eds. Berlin, Germany, W. De Gruyter, pp 1-30.

London, D., Wolf, M. B., Morgan, G. B., Gallego Garrido, M. (1999). Experimental silicate-phosphate equilibria in peraluminous granitic magmas, with a case study of the 
Albuquerque batholiths at Tres Arroyos, Badajoz, Spain. Journal of Petrology, 40, 215-240.

Marques, G. C. (2009). Geologia dos grupos Araí e Serra da Mesa e seu embasamento no sul de Tocantins. Dissertação (Mestrado). Brasília: Instituto de Geociências - UnB.

Moore, P. B. (1972). Sarcopside: its atomic arrangement. American Mineralogist, 57, 24-35.

Moore, P. B. (1984). Cristallochemical aspects of the phosphates minerals In: J. O. Nriagu, P. B. Moore (Eds.), Phosphate minerals (137-154).
Queiroz, H. (2016). Sistema granito-pegmatito Mata Azul, Tocantins/Goiás: geologia, gênese e mineralização. Tese (Doutorado). Brasília: Instituto de Geociências - UnB.

Roda-Robles, E., Pesquera, A. (2014). On the geochemical character of primary fe-mn phosphates belonging to the triphylite-lithiophilite, graftonite-beusite, and triplitezwieselite series : first results and implications for pegmatite petrogenesis. Canadian Mineralogist, 52, 321-335.

Scholz, R. (2006). Estudo dos fosfatos do Distrito Pegmatítico de Conselheiro Pena, Minas Gerais. Tese (Doutorado). Minas Gerais: Universidade Federal de Minas Gerais - UFMG. 